\title{
Blocked Voice Prosthesis: A Common Complication Reducing the Prosthesis Longevity
}

\author{
${ }^{1}$ Rajshekar Halkud, ${ }^{2}$ Ashok M Shenoy, ${ }^{3} \mathrm{KC}$ Sunil, ${ }^{4} \mathrm{M}$ Samskruthi, ${ }^{5}$ Jagdish Sarvadyna, ${ }^{6}$ Siddharth Biswas \\ ${ }^{7}$ Purshottam Chavan, ${ }^{8}$ KT Siddappa, ${ }^{9}$ Akshay Shivappa, ${ }^{10}$ Sudhir M Naik
}

\begin{abstract}
Background/Objectives: Mechanical prosthetic valve rehabilitation after total laryngectomy have a success rates of $90 \%$ in restoring voice. The effective speech is achieved better with mechanical voice prosthesis when compared to esophageal speech and electrolarynx. Candidal growth and tubal blockage are the commonest cause of peri and endotubal leakage causing prosthesis failure.
\end{abstract}

Case report: A 50-year-old male who had undergone wide field laryngectomy with primary tracheoesophageal puncture (TEP) with voice prosthesis 18 months back complained of blocked voice prosthesis and peritubal leakage. The tip of the cleaning brush which had blocked the opening was removed in the outpatients under topical anesthesia and the peritubal block reduced.

Conclusion: Mechanical valve prosthesis rehabilitation after primary tracheoesophageal puncture is the standard voice rehabilitation of laryngectomized patients. Patient education regarding maintenance of the prosthesis and the care for the tracheostoma is important in reducing the complications.

Keywords: Voice prosthesis, Tracheoesophageal puncture (TEP), Prosthesis brush, Peritubal leak.

How to cite this article: Halkud R, Shenoy AM, Sunil KC, Samskruthi M, Sarvadyna J, Biswas S, Chavan P, Siddappa KT, Shivappa A, Naik SM. Blocked Voice Prosthesis: A Common Complication Reducing the Prosthesis Longevity. Int $\mathrm{J}$ Head Neck Surg 2014;5(2):66-71.

Source of support: Nil

Conflict of interest: None

\section{INTRODUCTION}

Surgical procedures for obtaining pulmonary voice came to the rescue of total laryngectomy patients who had complete voice loss. ${ }^{1}$ These procedures had high complication rates with aspirations of pharyngeal contents into the airways. ${ }^{1}$

\footnotetext{
${ }^{1,7}$ Associate Professor, ${ }^{2}$ Professor and Head

${ }^{3-5,9,10}$ Fellow ${ }^{6}$ Professor, ${ }^{8}$ Assistant Professor

1-4,7-10Department of Head and Neck Oncosurgery, Kidwai Memorial Institute of Oncology, Bengaluru, Karnataka, India

${ }^{5}$ Department of Oral Oncosurgery, Kidwai Memorial Institute of Oncology, Bengaluru, Karnataka, India

${ }^{6}$ Department of Pathology, Kidwai Memorial Institute of Oncology Bengaluru, Karnataka, India
}

Corresponding Author: Sudhir M Naik, Fellow, Department of Head and Neck Oncosurgery, Kidwai Memorial Institute of Oncology, Bengaluru, Karnataka, India, Phone: 09916807109 e-mail: sud223@gmail.com
To overcome these complications mechanical valve devices inserted into the tracheoesophageal mucosa began to be used with the aim of obtaining an acceptable voice and also to prevent to prevent aspiration of saliva and food particles. ${ }^{2-4}$ Mechanical prosthetic voice rehabilitation after total laryngectomy has proven to be successful in restoring proper speech function in over $90 \%$ of patients and is nowadays the method of choice in most developed countries. ${ }^{5,6}$

Mechanical voice prosthesis is a silicone device placed in a fistula created through the tracheoesophageal wall either at the time of the primary operation or later as a second stage independent procedure. ${ }^{7}$ Effective speech production using the voice prosthesis is superior to the esophageal speech and electrolarynx. ${ }^{8,9}$

The average life of the prosthesis is 3 to 14 months and the common problems recommending a prosthesis replacement are incompetence of the prosthesis or tracheoesophageal puncture, the deterioration of the prosthesis due to fungal colonization, the emergence of mucoid crusts that impede a correct functioning and granulomas in the fistular path or tracheal mucosa. ${ }^{1,10}$ Also noted are persistent fistula inadequate to prosthesis diameter, cervical cellulitis, necrosis of the tracheoesophageal mucosa, stomal stenosis and dysphagia and granulomas in the orifice of the fistulas are seen ion 5 to $10 \%{ }^{1}$

Prosthesis speech is rated to be of enhanced quality with better intelligibility, higher restoration and longer phonatory time which seem to be unaffected by age or radiotherapy. ${ }^{11}$ These factors make TEP with prosthesis speech superior over the mechanical intonation of electrolarynx speech and the simplicity of training is preferred over the largely complex rehabilitation using esophageal speech. ${ }^{11}$ TEP prosthesis speech was initially advocated for esophageal or electrolaryngeal speech failed patients. ${ }^{11}$

Later it has evolved as a current standard in voice rehabilitation of alaryngeal patients performed at the time of total laryngectomy. ${ }^{11}$ Primary TEP introduction is more widely preferred over secondary as the provision of voice much earlier after the laryngectomy whereas reacquisition in secondary TEP is delayed after completion of subsequent adjuvant treatment like radiotherapy or chemoradiotherapy. ${ }^{11}$ We report a case of blockage of the prosthesis by the broken 
impacted cleaning brush used to clean it which was successfully removed at the outpatients.

\section{CASE REPORT}

A 50-year-old male who had undergone wide field laryngectomy with primary TEP and prosthesis implantation 18 months back came for follow-up with history of blocked prosthesis. Earlier he had come with 3 months history of difficulty in swallowing and change in voice where he was diagnosed as tumor in the left pyriform fossa under mirror examination.

X-ray soft-tissue neck revealed irregular soft-tissue opacity seen in the pyriform fossa extending into the aryepiglottic fold and epiglottis. Rest of the soft-tissues were normal and anterior osteophytes were seen (Figs 1 and 2). 2D echocardiography and color Doppler study were normal with normal LV function and wall motion.

On contrast enhanced CT neck a large well-defined homogenous enhancing soft-tissue attenuating mass lesion was seen in the left pyriform fossa with pre-epiglottic space extension, thyroid cartilage infiltration with extension to the strap muscles. The lateral wall of the fossa was spared with no subglottic extension. Left sided level II, III lymphadenopathy were seen. Ultrasound guided translaryngeal fine needle aspiration biopsy revealed squamous cell carcinoma with spindle cell morphology.

Direct laryngoscopic evaluation and frozen section analysis showed poorly differentiated squamous cell carcinoma in the left pyriform fossa, later proceeded with tracheostomy and wide field laryngectomy. Intraoperatively interjugular clearance was done with preservation of the right thyroid. Primary TEP was done after cricopharyngeal myotomy.
Voice prosthesis was placed and the neopharynx created with three layers $\mathrm{T}$ closure.

Histomicroscopic examination reported squamous cell carcinoma Grade I of the left pyriform fossa. All the cut margins were free of the tumor. Left paraglottic space was involved, epiglottic and pre-epiglottic adipose tissue was free of tumor. Thyroid and cricoids cartilages and the thyroid glands were free of tumor. All the level II and III and the para and pretracheal lymph nodes were not involved by tumor. The patient was advised postoperative radiotherapy with intensity modulated radiotherapy 66 gy over 33 fractions with five cycles of chemotherapy. Five cycles of intravenous carboplatin $150 \mathrm{mg}$ weekly were given.

He received speech therapy and voice rehabilitation and was going well till recently he had blocking of the voice prosthesis while cleaning and later developed a peritubal leak. Plain X-ray chest revealed the piece of the brush used for cleaning to be lodged in the prosthesis and blocking it. Also, the metal wire of the brush to be visible in the stomal opening.

After applying topical anesthesia the tip of the metal wire brush was removed using a curved artery forceps (Fig. 3). The patient was advised cleaning of the prosthesis by a new brush and advised nystatin mouth gargles for a week. Follow-up with regular cleaning of the prosthesis with the antifungal gargles reduced the peritubal leaks and made the prosthesis functioning.

\section{DISCUSSION}

Voice and communication skills rehabilitation after total laryngectomy has been revolutionized by the widespread use of mechanical voice prostheses. ${ }^{2-4}$

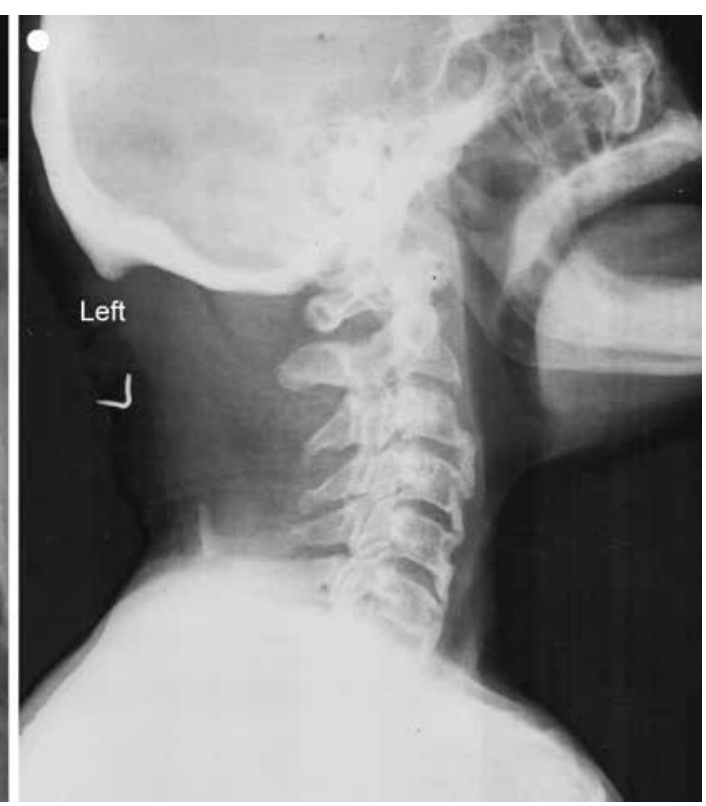

Fig. 1: Foreign body seen in the mechanical prosthesis in the tracheoesophageal puncture area 


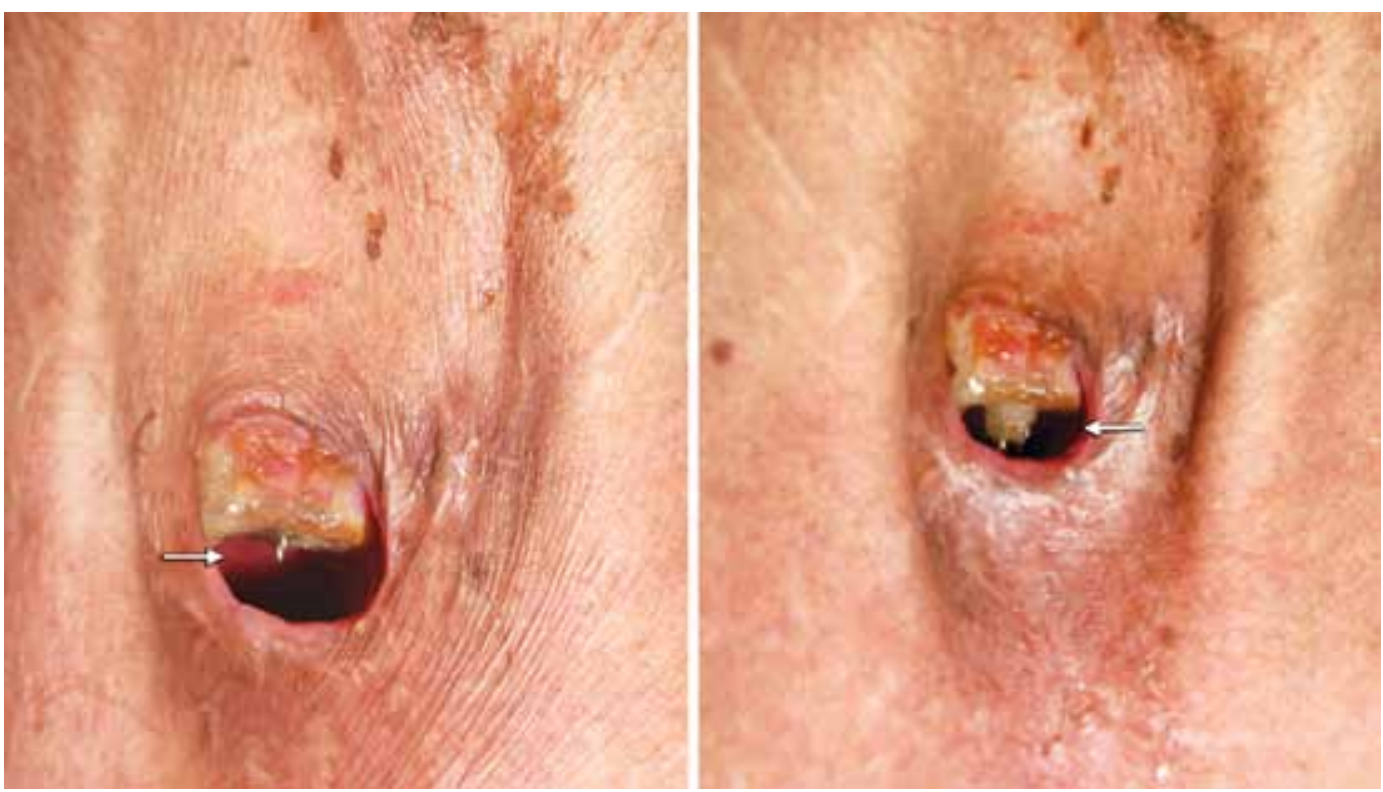

Fig. 2: Foreign body, the broken cleaning brush seen
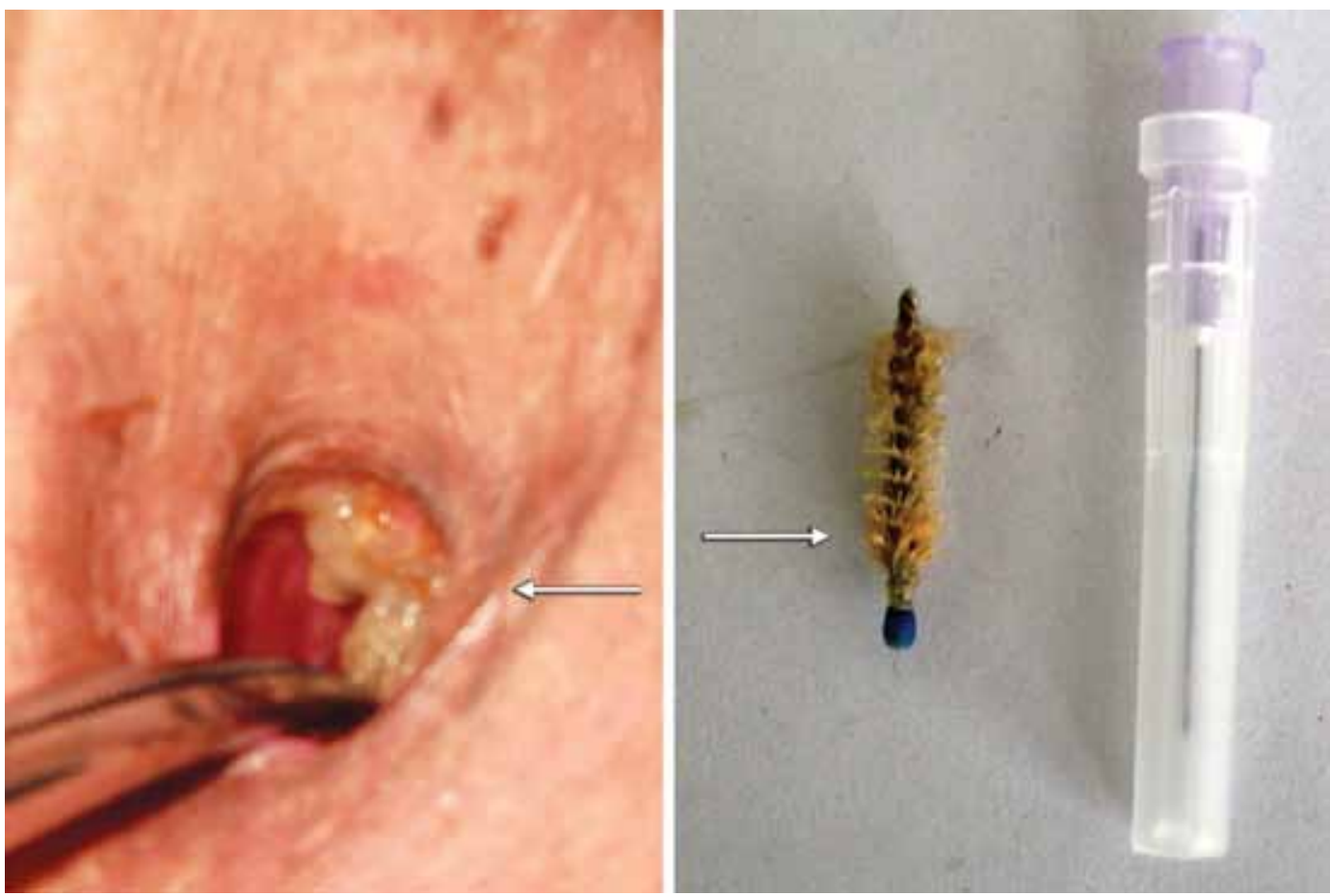

Fig. 3: Removal under topical anesthesia in the outpatients

Total laryngectomy represents a significant burden on patients function and cosmesis but the greatest concern is the profound impact on phonation. ${ }^{10}$

Rehabilitation is aimed at diminishing psychological and social distress with ensuring improvement of quality of life. ${ }^{12-14}$

The results obtained through the use of these voice prostheses have been increasing steadily and currently reach over $70 \%$ effectiveness. ${ }^{15,16}$ Alaryngeal patients are rehabilitated by electrolaryngeal speech, esophageal speech and tracheoesophageal speech via TEP and mechanical voice prosthesis. ${ }^{10}$ Electrolarynx needs lesser expertise but gives a mechanical tone to the voice produced. ${ }^{10}$ Esophageal speech requires great patient motivation in mastering the technique. ${ }^{10}$ Mechanical voice prosthesis introduced after TEP is a silicon based semipermanent implant requiring occasional replacement. ${ }^{10}$

The new generation prosthesis with an average lifespan of several months only can be replaced at the outpatients and less than $3 \%$ of patients require general anesthesia for this change. ${ }^{1,17}$ Complications are minimal which include colonization of the pharynx with Candida causing leakage around the prosthesis, displacement, intractable aspiration of secretions, granulation tissue, tracheostomal stenosis and widening of the tracheoesophageal fistula. ${ }^{18}$ 
Periprosthesis leakage is reported to the extent of $73 \%$ and seen in both primary and secondary may be due to tracheoesophageal wall thinning or fistula widening. ${ }^{10}$ Also increased diameter of the fistuloplasty compared to that of the prosthesis is reason behind periprosthetic leaks. ${ }^{19,20}$ Periprosthetic leak can be managed surgically but endoprosthetic leaks needs a change of prosthesis. ${ }^{21}$

Periprosthetic granulation tissue is also a common complication seen in 7 to $17.4 \%$ of voice prostheses carriers which can be corrected with resection or vaporization of hypertrophic tissue by silver nitrate application or KTP or $\mathrm{CO}_{2}$ laser. ${ }^{22}$ Cheng et al did not find any significant difference with respect to complications between primary and secondary TEPs prosthesis in their 68 cases retrospective study. ${ }^{23}$ They noted prosthesis failure when a leakage through it was seen and fistula widening or thinning when leak around it was seen. ${ }^{24,25}$ Candidal biofilms on the esophageal surface of the prosthesis is the main cause of valve loosening and leakage requiring replacement. ${ }^{26}$ Nystatin suspension cleaning of the prosthesis to limit Candida colonization which cause blockage and leaks, purse string suturing around the fistula are also advised however their efficacy are doubtful. ${ }^{26}$

Tracheostomal stenosis seen in $28 \%$ causing difficulty in prosthesis cleaning warrant stomal revision. ${ }^{10}$ Stenosis are more seen in females with small diameter trachea, also depend on technique of tracheal resection, infection at the mucocutaneous junction scarring. ${ }^{10}$ Prosthesis aspiration in the tracheobronchial tree is seen in 0.75 to $13 \%{ }^{10}$

Reports of multiple episodes of bronchial aspiration of the prosthesis necessitating bronchoscopic removal of the foreign body have been reported. ${ }^{10}$ Poor selection of the size of the prosthesis and fistula widening seen in 20 to $39 \%$ were responsible for these aspiration..$^{25}$ Replacement should be always done by the surgeon only and never by the patient. ${ }^{7}$ The puncture site should be closed in cases of intractable leakage, recurrent prosthesis dislodgement with bronchial aspiration, phonatory failure and persistent severe pain. ${ }^{10}$

Chone, Casso and Boscolo-Rizzo, et al in their independent studies reported no significant influence of radiotherapy on the success rate on primary or secondary TEP. ${ }^{27-30}$ Norsuhazenah et al reported postoperative radiotherapy have an increased tendency for developing complications. ${ }^{10}$ Primary TEP following salvage laryngectomy is a significant risk factor for pharyngocutaneous fistula in post chemoradiotherapy patients. ${ }^{10}$

A laryngectomized patient with a permanent tracheal stoma should realize that the stoma is now part of their airway and it renders direct and easy access to their lower tracheobronchial tree, and also increases the risk of aspiration. $^{31}$
Patients should also know that the negative intrapleural pressure gradient that is generated during deep breathing or paroxysms of coughing may cause aspiration of an object held loosely around the stoma. ${ }^{32}$ Careful handling of objects around the stoma after laryngectomy is important in preventing complications. ${ }^{31}$ Xerostomia induced by radiotherapy reduce prosthesis lifespan as it decreases antibacterial and antifungal salivary peptides, which increases the chance of biofilm formation. ${ }^{26}$

Trudeau et al, Artázkoz del Toro and López Martínez found no difference in lifespan of prosthesis in patients with radiotherapy or those without. ${ }^{33,34}$ Pattani et al found existence of gastroesophageal reflux and the development of granulation tissue leading to leaks. ${ }^{35}$ Good results were obtained with aggressive antireflux therapy. ${ }^{35}$

TEP with prosthesis can be done primarily at time of total laryngectomy or later as a secondary procedure. ${ }^{27}$ Primary has a better success rate with immediate reacquisition of speech. ${ }^{27-30}$ Success rates on a long-term basis is defined as use of TEP speech consistently for the majority of verbal communication and literature is 78 to $96 \%$ in primary and 70 to $75 \%$ in secondary. ${ }^{27-30}$ Short-term success rates defined as the immediate acquisition of intelligible speech is 67 to $100 \%$ in primary TEP and 50 to $100 \%$ in secondary TEP. ${ }^{27-30}$

The patients with secondary TEP use the prosthesis for longer duration compared to primary as the earlier have completed treatment and are observed for longer time with more motivation and lower expectations of normal voice acquisition. ${ }^{36}$ Foreign bodies can be aspirated like nuts, vegetable matter, bones, metal and plastic objects, pills, safety pins, turban scarf pins, plastic spoons, fishing weight, cockroaches, straight pin and small plastic objects. ${ }^{31}$

Removal of these aspirated foreign bodies are usually done by rigid bronchoscopy and sometimes removal may be difficult in permanent stoma, with a high percentage of these requiring a thoracotomy, especially for the removal of sharp objects such as pins, wild barley, coarse cloth or a fractured tracheostomy tube. ${ }^{37}$

Initial flexible bronchoscopy may be tried if the FB is higher and sometimes even rigid bronchoscopy may be risky officiating the need for open surgery. ${ }^{31}$

Flexible bronchopic removal can be done easily under local anesthesia with 86 to $90 \%$ success rates. ${ }^{38,39}$ Technical improvement with videobronchoendoscopy, a broad variety of forceps and safer anesthesia has reduced the post bronchoscopic removal complication to less than $5 \%{ }^{31}$ The aspiration of the prosthesis to the bronchial tree and its intake into the digestive system have also been described, along with the emergence of local abscesses or infectious mediastinitis associated with TEP. ${ }^{5,40}$ 


\section{CONCLUSION}

Mechanical valve prosthesis rehabilitation after primary TEP is the standard voice rehabilitation of laryngectomized patients. Patient education regarding maintenance of the prosthesis and the care for the tracheostoma is important in reducing the complications. The fistula arising from prosthesis dislodgement should be managed promptly to reduce subsequent morbidity.

\section{REFERENCES}

1. González-García JA, Aguirregaviria JI. Total voice prosthesis incarceration in the tracheoesophageal mucosa. Report of a new complication when using phonatory prostheses. Acta Otorinolaringol Esp 2010;61(3):220-224.

2. Singer MI, Blom ED. An endoscopic technique for restoration of voice after laryngectomy. Ann Otol Rhinol Laryngol 1980;89: 529-533.

3. Hilgers FJ, Schouwenburg PE. A new low-resistance, selfretaining prosthesis (Provox) for voice rehabilitation after total laryngectomy. Laryngoscope 1990;100:1202-1207.

4. Annyas AA, Nijdam HF, Escajadillo JR, Mahieu HF, Leever H. Groningen prosthesis for voice rehabilitation after laryngectomy. Clin Otolaryngol Allied Sci 1984;9:51-54.

5. Coul BM, Hilgers FJ, Balm AJ, Tan IB, Hoogen FJ, van TH. A decade of postlaryngectomy vocal rehabilitation in 318 patients: a single Institution's experience with consistent application of provox indwelling voice prostheses. Arch Otolaryngol Head Neck Surg 2000 Nov;126(11):1320-1328.

6. Bunting GW. Voice following laryngeal cancer surgery: troubleshooting common problems after tracheoesophageal voice restoration. Otolaryngol Clin North Am 2004 Jun;37(3):597-612.

7. Puttasiddaiah P, Berry S, Kumar M. The missing speaking valve. Int J Otorhinolaryngol 2006;4(2):4772-4774.

8. Kesteloot K, Nolis I, Huygh J, Delaere P, Feenstra L. Costs and effects of tracheoesophageal speech compared with esophageal speech in laryngectomy patients. Acta Otorhinolaryngol Belg 1994;48:387-394.

9. Quer M, Burgues-Vila J, Garcia-Crespillo P. Primary tracheoesophageal puncture vs esophageal speech. Arch Otolaryngol Head Neck Surg 1992;118:188-190.

10. Norsuhazenah PSD, Baki MM, Yunus MRM, Athar PPSH, Abdullah S. Complications following tracheoesophageal puncture: a tertiary hospital experience. Ann Acad Med Singapore 2010;39:565-568.

11. Terada T, Saeki N, Toh K, Uwa N, Sagawa K, Takayasu S, et al. Voice rehabilitation with Provox2 voice prosthesis following total laryngectomy for laryngeal and hypopharyngeal carcinoma. Auris Nasus Larynx 2007;34:65-71.

12. Kazi R, De Cordova J, Singh A, Venkitaranam R, Nutting CM, Clarke P. Voice-related quality of life in laryngectomees: assessment using the VHI and V-ROQL symptom scales. Voice 2007; 21:728-734.

13. Lundstrom E, Hammarberg B, Munck-Wikland E. Voice handicap and health-related quality of life in laryngectomees: assessments with the use of VHI and EORTC questionnaires. Folia Phoniatr Logop 2009;61:83-92.

14. Armstrong E, Isman K, Dooley P, Brine D, Riley N, Dentice R, et al. An investigation into the quality of life of individuals after laryngectomy. Head Neck 2001;23:16-24.
15. Delsupehe K, Zink I, Lejaegere M, Delaere P. Prospective randomized comparative study of tracheoesophageal voice prosthesis: blom-singer versus provox. Laryngoscope 1998;108: 1561-1565.

16. González-Poggioli N, González-Botas JH, Vázquez-Barro JC, Novoa-Juiz V, Martínez-Vidal J. Fístulas fonatorias hoy. Acta Otorrinolaringol Esp 2007;58:110-112.

17. Schafer P, Klutzke N, Schwerdtfeger FP. Voice restoration with voice prosthesis after total laryngectomy. Assessment of survival time of 378 Provox-1, Provox-2 and Blom-Singer voice prosthesis. Laryngorhinootologie 2001 Nov;80(11):677-681.

18. Stafford FW. Current indications and complications of tracheoesophageal puncture for voice restoration after laryngectomy. Curr Opin in Otolaryngol Head Neck Surg 2003;11:89-95.

19. Van Den Hoogen FJ, Oudes MJ, Hombergen G, Nijdam HF, Manni JJ. The groningen, nijdam and provox voice prostheses: a prospective clinical comparison based on 845 replacements. Acta Otolar 1996;116:119-124.

20. Issing WJ, Fuchshuber S, Wehner M. Incidence of tracheooesophageal fistulas after primary voice rehabilitation with the provox or the Eska-Herrmann voice prosthesis. Eur Arch Otorhinolaryngol 2001;258:240-242.

21. Rokade AV, Mathews J, Reddy KT. Tissue augmentation using bioplastique as a treatment of leakage around a provox 2 voice prosthesis. J Laryngol Otol 2003;117:80-82.

22. Smith WK, Pfleiderer AG. The use of KTP Laser in the management of hypertrophic tracheal mucosa and granulation tissue around Provox valve prostheses. J Laryngol Otol 2003; 117:6062.

23. Cheng E, Ho M, Ganz C, Shaha A, Boyle JO, Singh B, et al. Outcomes of primary and secondary tracheoesophageal puncture: a 16-year retrospective analysis. Ear Nose Throat J 2006;85: 264-267.

24. Tantawy A. Long-term results of provox voice prosthesis for voice rehabilitation after total laryngectomy a 7 years experience. Int Congress Series 2003;1240:871-877.

25. Hathurusinghe H, Uppal H, Shortridge R, Read C. Case of the month: a dislodged tracheoesophageal valve: importance of rapid replacement or stenting. Emerg Med J 2006;23:322-323.

26. Mahieu HF, Van Saene JJ, Den BJ, Van Saene HK. Oropharynx decontamination preventing Candida vegetation on voice prostheses. Arch Otolaryngol Head Neck Surg 1986 Oct;112(10): 1090-1092.

27. Chone CT, Gripp FM, Spina AL, Crespo AN. Primary vs secondary tracheoesophageal puncture for speech rehabilitation in total laryngectomy: long-term results with indwelling voice prosthesis. Otolaryngol Head Neck Surg 2005;133:89-93.

28. Cheng E, Ho M, Ganz C, Shaha A, Boyle JO, Singh B. Outcomes of primary and secondary tracheoesophageal puncture: a 16-year retrospective analysis. Ear Nose Throat J 2006;85: 264-267.

29. Boscolo-Rizzo P, Zanetti F, Carpene S, Da Mosto MC. Long-term results with tracheoesophageal voice prosthesis: primary versus secondary TEP. Eur Arch Otorhinolaryngol 2008;265:73-77.

30. Geraghty JA, Wenig BL, Smith BE, Portugal LG. Long-term follow-up of tracheoesophageal puncture results. Ann Otol Rhinol Laryngol 1996;105:501-503.

31. Uzaslan E, Ursavaş A, Ediger D, Karadăg M. An unusual way of tracheal stoma cleaning could end up with foreign body aspiration in a laryngectomized patient: Tüberküloz ve Toraks Dergisi 2005;53(1):61-64. 
32. Nwiloh J, Fortson J. Aspirated foreign body in a laryngectomized patient: case report and literature review. Ear Nose Throat J 2001; 80:744-746.

33. Trudeau MD, Schuller DE, Hall DA. The effects of radiation on tracheoesophageal puncture: a retrospective study. Arch Otolaryngol Head Neck Surg 1989;115:1116-1117.

34. Artazkoz del Toro JJ, López Martínez R. Rehabilitación quirúrgica de la voz: influencia de la radioterapia postoperatoria en la fístula traqueoesofágica. Acta Otorrinolaringol Esp 1997;48: 299-304.

35. Pattani KM, Morgan M, Nathan CA. Reflux as a cause of tracheoesophageal puncture failure. Laryngoscope 2009;119:121-125.

36. Mendenhall WM, Morris CG, Stringer SP, Amdur RJ, Hinerman RW, Villaret DB, et al. Voice rehabilitation after total laryngectomy and postoperative radiation therapy. J Clin Oncol 2002;20:2500-2505.

37. Otto RA, Davis W. Tracheostomy tube fracture: an unusual etiology of upper respiratory airway obstruction. Laryngoscope 1985;95:980-981.

38. Rafanan AL, Mehta AC. Adult airway foreign body removal. What's new? Clin Chest Med 2001;22:319-330.

39. Clark PT, Williams TJ, Teichtahl H. Removal of proximal and peripheral endobronchial foreign bodies with the flexible fibreoptic bronchoscope. Anaes Intensive Care 1989;17:205-208.

40. Laccourreye $\mathrm{O}$, Mènard $\mathrm{M}$, Crevier-Buchman L, Couloignier V, Brasnu D. In situ lifetime, causes for replacement and complications of the Provox voice prosthesis. Laryngoscope 1997; 107:527-530. 